\title{
Influence of Polyphenol Levels on the Perception of Aroma in Vitis vinifera cv. Malbec wine
}

\author{
M.C. Goldner ${ }^{*}$, P. di Leo Lira², C. van Baren ${ }^{2}$, A. Bandoni
}

(1) Instituto para la Investigación de la Industria Química, Consejo Nacional de Investigaciones Científicas y Técnicas (INIQUICONICET), Av. Bolivia 5150, (A4408FVY) Salta, Argentina

(2) Cátedra de Farmacognosia (IQUIMEFA), Facultad de Farmacia y Bioquímica, Universidad de Buenos Aires, Junín 956, (C1113AAD) Buenos Aires, Argentina

Submitted for publication: May 2010

Accepted for publication: July 2010

Key words: Sensory characterisation, Malbec wine, SPME-GC-MS, polyphenol, principal component analysis

\begin{abstract}
The aim of this study was to explore the effect of two ranges of polyphenols naturally present in Malbec wine, high concentrations (4.5-7.2 g/L) and low (1.4-3.2 g/L), on the perception of aroma. Samples with a maximum ethanol level of $\mathbf{1 3 . 5 \%}$ were taken from the fermentation tanks before the clarification and filtration process. A Quantitative Descriptive Analysis of wines was assessed by ten trained assessors, and HS-SPME-GC-MS and physicochemical analyses were performed. The intensities of fruity $(P<0.01)$, citrus $(P<0.01)$, strawberry $(P$ $<0.05)$, cooked fruit $(P<0.01)$ and floral $(P<0.01)$ aromas decreased when the level of polyphenols increased. Neither volatile compounds nor physicochemical analyses were significant in the two groups of wines.
\end{abstract}

\section{INTRODUCTION}

Flavour results from the integration of aroma, taste and chemosensory information within the brain; it is a multisensory stimulus that, in wine, is greatly dependent on the volatile substances present both in the sample matrix and in the headspace. Polyphenols are major non-volatile components in red wine that contribute to mouth-feel properties or interact with volatile compounds in solution (Aronson \& Ebeler, 2004). The polyphenol content of wine has been widely recorded as responsible for astringency and bitterness (Arnold \& Noble, 1978; Gawel, 1998; Monteleone et al., 2004; Vidal et al., 2004; Lesschaeve \& Noble, 2005; Condelli et al., 2006), but its effect on aroma perception has been evaluated to a lesser extent.

Several studies that focused on the study of volatile compounds, their relation with perceived aroma and the effect of certain polyphenols have been carried out. Dufour and Bayonove (1999) investigated the influence of catechins and a wine with a highly condensed tannin fraction on the volatility of aromatic substances using a dynamic headspace technique; although the tannin fraction induced a slight decrease of benzaldehyde volatility and a salting out of limonene, it had no effect on the volatility of isoamyl acetate and ethyl hexanoate. More recently, Aronson and Ebeler (2004) investigated the action of polyphenol concentrations in the headspace and perceived aroma intensity by Headspace Solid Face Microextraction (HS-SPME) and sensory methods. They found that gallic acid significantly decreased the volatility of 2-methylpyrazine while naringin had less effect. Furthermore, when tannins were added to wines, an effect on flavour volatility was detected by gas-chromatography (GC) analysis, but this was less evident through sensory evaluation.

Lund et al. (2009) found that the perception of isobutyl methoxypyrazine, 3-mercaptohexanol and ethyl decanoate was largely suppressed by the addition of polyphenols, while the perception of 3-mercaptohexanol was accentuated with a caffeic acid addition in Sauvignon Blanc wines. Notably, the mentioned studies were conducted in aqueous "model wine" solutions or in a base wine with additional wine-derived compounds. All authors have stressed the need to imitate the real context, but none of the studies were assessed with authentic wine samples, except the recent work by Sáenz-Navajas et al. (2010), who studied the effect of the non-volatile matrix on the aroma perception of white and red wines by combining different volatile and non-volatile extracts.

SPME has become a popular method for selectively extracting and concentrating analytes without the use of solvents (Pawliszyn, 1999); the fibres being available in different coating combinations enlarges the field of possible applications (Dietz et al., 2006). This is a simple method that allows a parallel with the process of olfaction and making use of multivariate analysis tools such as Principal Component Analysis makes good differentiation and characterisation possible.

The aim of the current study was to explore the effect of two ranges of polyphenols, high (4.5-7.2 g/L) and low (1.4-3.2 g/L), that are naturally present in Malbec wine on the perception of aroma. The cut-off values for high and low polyphenol content were determined according to levels found in non-commercial and commercial wines respectively (Faitová et al., 2004). 


\section{MATERIALS AND METHODS \\ Wine samples}

The results of our previous work have shown that the ethanol level is an important factor that could affect the detection of a wine's volatile compounds and the perception of aroma attributes when it surpasses $14.5 \%$ (Goldner et al., 2009). For this reason, twenty-eight Malbec wine samples (Vitis vinifera cv. Malbec) were selected from a set of fifty-six with an ethanol percentage of less than 14.5\%. The ethanol (AOAC, 1990) ranged from $10.5 \%$ to $13.5 \%$. Grapes were harvested during March 2004 at 23 to $25^{\circ} \mathrm{B}$, from vineyards of between 10 and 12 years maturity; fermentation times had been 7 to 10 days, maceration times 13 to 21 days and no malolactic fermentation or wood treatment had occurred (These data were supplied by each winery). Samples were obtained from fermentation tanks after maceration and before clarification and filtration, and were provided by twenty-eight different wineries from seven viticulture regions in Argentina (seven from Alto Río Mendoza; five each from Patagonia, San Juan, Valle de Uco; three from Mendoza del Este; two from Mendoza del Sur; and one from Valles Calchaquíes). The following specifications (AOAC, 1990) were applied: 20.9 to $32.3 \mathrm{~g} / \mathrm{L}$ dry extract, 3.56 to 5.93 $\mathrm{g} / \mathrm{L}$ tritatable acidity, 1.80 to $4.10 \mathrm{~g} / \mathrm{L}$ reducing sugars and 3.28 to $4.21 \mathrm{pH}$.

The samples were classified into two groups according to their total polyphenol concentration (Folin-Ciocalteau method), taking into account information from Faitová et al. (2004): polyphenol levels found in commercial wines (1.4-3.2 g/L; samples No. 1 to 12 ) and polyphenol levels up to (4.5-7.2 g/L; samples No. 13 to 28). These, we will call "low" and "high" when referring to these two ranges respectively.

First, a sensory experiment was conducted in order to avoid esters hydrolysis or phenolic changes; then, samples were frozen at $-18^{\circ} \mathrm{C}$ until chromatography and physicochemical determinations were completed.

\section{Total polyphenols}

Total polyphenols were determined by the Folin-Ciocalteau method (Folin-Ciocalteau reagent, Merck KgaA Darmstadt, Germany) and the results were expressed in gallic acid equivalent (GAE) g/L. Absorbance (spectrophotometer Shimadzu PharmaSpec UV-1700) of each wine $(5 \mathrm{~mL})$ diluted 1:10, as well as the absorbance of gallic acid standards in concentrations of $0,0.05,0.10,0.15,0.25,0.50,1.00,1.50,2.50,5.00,7.00$ and $7.50 \mathrm{~g} / \mathrm{L}$, were determined at $760 \mathrm{~nm}$ against a reagent blank. Measurements were taken in duplicate and averaged. A calibration curve showing the absorbance/concentration of gallic acid was used to determine the GAE for wines.

\section{HS-SPME isolation of volatile compounds}

A Supelco fibre holder (Bellefonte, PA, USA) with a $100 \mu \mathrm{m}$ polydimethylsiloxane (PDMS) coated fused-silica fibre, was used for adsorbing volatile compounds from the head space of properly conditioned samples. Before extraction, the fibre was conditioned for $30 \mathrm{~min}$ at $250^{\circ} \mathrm{C}$ in the injection port of the gas chromatograph. Samples $(8 \mathrm{~mL})$ were placed into a 20 $\mathrm{mL}$ amber glass vial (Varian), saturated with sodium chloride $(2.0 \mathrm{~g})$ and then capped with a septum. Each wine sample was heated to $40^{\circ} \mathrm{C}$ and sonicated for $30 \mathrm{~min}$ in an ultrasonic bath (Branson 2510) with the fibre introduced into the glass vial headspace (Goldner et al., 2009). After equilibration, the fibre was removed from the sample and the analytes were thermally desorbed in the injection port of the GC-FID-MS instrument for analysis.

\section{GC-FID-MS analysis}

Aroma compounds were analysed by means of a GC-FID-MS apparatus with a special configuration (Retta et al., 2009): A Perkin Elmer Clarus 500 equipped with one injector (split/ splitless) was connected using a flow splitter to two capillary columns (J\&W, Scientific): a) polyethylene glycol PM ca. 20.000 , and b) $5 \%$ phenyl-95\% methyl silicone, both $60 \mathrm{~m}$ x $0.25 \mathrm{~mm}$ with $25 \mu$ of fixed phase. The polar column was connected to a FID, while the non-polar column was connected to a FID and a quadrupolar mass detector $(70 \mathrm{eV})$ by a vent system (MSVent ${ }^{\mathrm{TM}}$ ). The whole system operated at a constant flow of $1.87 \mathrm{~mL} / \mathrm{min}$., with Helium being used as the gas carrier. The injector temperature was set at $255^{\circ} \mathrm{C}$ for splitless injection. The sampling time was $3 \mathrm{~min}$. The column temperature was programmed according to the following: $40^{\circ} \mathrm{C}$ for $5 \mathrm{~min}$, increasing by $6^{\circ} \mathrm{C} / \mathrm{min}$ to $230^{\circ} \mathrm{C}$ and maintained for $13 \mathrm{~min}$. Both FID temperatures were $240^{\circ} \mathrm{C}$, and the temperatures for the transference line and ionic source were set at $180^{\circ} \mathrm{C}$ and $150^{\circ} \mathrm{C}$, respectively. Mass range $(\mathrm{m} / \mathrm{z})$ was $40-350 \mathrm{Da}$.

Identification of the compounds was taken from the retention indices (relative to $\mathrm{C}_{8}-\mathrm{C}_{24} n$-alkanes) obtained from both columns and compared with those of reference compounds, and by comparison of mass spectra using the usual libraries (Wiley/Nist, 2005; Adams, 2007). The mass spectra were obtained from reference compounds. The relative percentage contribution of the compounds was calculated from the total ion chromatograms by a computerised integration, assuming all of the response factors were 1 .

\section{Sensory analysis \\ Panel training}

Ten paid blinded judges (four females and six males, of 21 to 55 years old) from the panel of the Staffing and Training Group (a Buenos Aires consulting company), were trained in descriptive analysis of Malbec wine. During the training period (five sessions of two hours) judges performed the following tasks: 1) aroma identification using extracts diluted in water with $2 \%$ ethanol (IRAM 20006, 1996); 2) aroma identification using standard solutions in wine; 3) use of structure scale. These panellists had prior experience in quantitative descriptive analysis of milk, mayonnaise, dairy and perfumery products.

\section{Descriptive analysis}

The Descriptive Analysis (Stone \& Sidel, 1993; ASTM, 1992) was made using a 9-point intensity scale ranging from low to high. The panel leader received the scores orally (to simplify the work of blinded judges) and recorded them on a sheet of paper). Samples were tested in a conditioned room on individual tables. All samples $(50 \mathrm{~mL})$ were from a single bottle $(750 \mathrm{~mL})$ and were presented at $18 \pm 2{ }^{\circ} \mathrm{C}$ in transparent tulip-shaped glasses, covered with glass petri dishes and identified by random threedigit codes. A randomised incomplete block design was used to evaluate all the wines (the original set of fifty-six) and eight samples were presented for the session in the morning $(2.5 \mathrm{~h})$ and this was duplicated in the afternoon $(2.5 \mathrm{~h})$. The following 
TABLE 1

ANOVA of the mixed model of sensory data.

\begin{tabular}{|c|c|c|c|c|c|c|}
\hline \multicolumn{7}{|c|}{ ANOVA $P$-values } \\
\hline & Replication & Wine & Assessor & $\mathbf{R} \times \mathbf{W}$ & $\mathbf{R} \times \mathbf{A}$ & $\mathbf{W} \times \mathbf{A}$ \\
\hline df & 1 & 27 & 9 & 27 & 9 & 243 \\
\hline Fruity & 0.521 & 0.122 & $0.001 * *$ & 0.265 & 0.902 & $0.024^{*}$ \\
\hline Citrus & 0.962 & $0.001 * *$ & 0.169 & 0.113 & 0.307 & $0.006 * *$ \\
\hline Strawberry & 0.281 & $0 * * *$ & $0 * * *$ & 0.624 & 0.735 & $0.008 * *$ \\
\hline Plum & $0.007 * *$ & 0.316 & $0 * * *$ & 0.063 & 0.947 & 0.066 \\
\hline Raisin & $0.008 * *$ & $0.026^{*}$ & $0.001 * *$ & 0.721 & 0.738 & $0.006 * *$ \\
\hline Spicy & 0.129 & $0.006^{* *}$ & $0.004 * *$ & 0.444 & 0.432 & 0.270 \\
\hline Cooked fruit & 0.470 & $0.002 * *$ & 0.126 & 0.968 & 0.897 & $0.012 *$ \\
\hline Floral & 0.847 & $0.014^{*}$ & $0.024 *$ & 0.091 & 0.366 & $0.014 *$ \\
\hline Honey & 0.595 & $0 * * *$ & $0.005 * *$ & 0.213 & 0.690 & 0.122 \\
\hline Herby & $0.031 *$ & $0 * * *$ & $0 * * *$ & $0.026^{*}$ & 0.826 & $0.037 * *$ \\
\hline Sweet pepper & 0.295 & 0.256 & 0.058 & 0.295 & 0.204 & 0.150 \\
\hline
\end{tabular}

$* \mathrm{p}<0.05 * * \mathrm{p}<0.01 * * * \mathrm{p}<0.001$

df: degrees of freedom

Error df: 243

$\mathrm{R}$ : replication

W: wine

A: assessor

TABLE 2

Mean sensory attributes from two polyphenol ranges of 28 wines.

attributes were selected for descriptive analysis: fruity, citrus, strawberry, plum, raisin, cooked fruit, floral, honey, herby, spicy and sweet pepper. (For more details of how these attributes were selected, see Goldner and Zamora, 2007.)

\section{Data analysis}

The assessors' performance was studied using an ANOVA model, in which the assessor was considered a random factor, wine and replication as fixed factors and with double replication $\mathrm{X}$ assessor, replication $\mathrm{X}$ wine and wine $\mathrm{X}$ assessor interactions. An analysis of variance (ANOVA) was carried out to assess attributes, volatile compounds and physicochemical characteristics that were significantly different among wines where polyphenol levels were considered a fixed factor. A Pearson correlation was calculated between sensory and GC data. The Principal Component Analysis (PCA) of both the average panel and GC data was evaluated to compare the relationship among sensory attributes and volatile compounds. A covariance matrix was used and the minimum eigenvalue was set at 1. All data were processed using Infostat version 2009p.

\section{RESULTS AND DISCUSSION}

\section{Panel performance}

The results of the ANOVA of sensory data are summarised in Table 1. Sources of variation were replication, wine, assessor and double interactions. Each wine was evaluated by ten assessors for duplication (28 wines X 10 assessors X 2 replications = 560 observations). Replication $\mathrm{X}$ assessor interactions were non-significant, indicating that assessors were consistent in their judgments. The judges showed good reproducibility; replication $\mathrm{X}$ wine interactions were non-significant except for herby aroma. Assessors displayed significant $(P<0.05)$ effect in most of the attributes; this means they evaluated samples in a different way, but their assessments were consistent between two replications. Wine $\mathrm{X}$ assessor interactions were significant $(P<0.05)$ for citrus, strawberry, raisin, cooked fruit, floral and herby attributes. Tang et al. (1999) and Zamora and Guirao

\begin{tabular}{lcc}
\hline \multicolumn{1}{c}{ Attribute } & \multicolumn{2}{c}{$\begin{array}{c}\text { Mean sensory attribute from } \\
\text { polyphenol ranges }(\mathbf{g} / \mathbf{L})\end{array}$} \\
& $\mathbf{4 . 5 - 7 . 2}$ & $\mathbf{1 . 4 - 3 . 2}$ \\
\hline Fruity & $2.18 \pm 0.14$ & $2.93 \pm 0.19^{* *}$ \\
Citrus & $1.37 \pm 0.14$ & $2.32 \pm 0.28^{* *}$ \\
Strawberry & $2.46 \pm 0.19$ & $3.20 \pm 0.33^{*}$ \\
Plum & $2.93 \pm 0.13$ & $3.34 \pm 0.29$ \\
Raisin & $2.22 \pm 0.17$ & $2.25 \pm 0.34$ \\
Spicy & $2.54 \pm 0.23$ & $2.05 \pm 0.28$ \\
Cooked fruit & $1.73 \pm 0.15$ & $2.78 \pm 0.31^{* *}$ \\
Floral & $1.85 \pm 0.11$ & $2.68 \pm 0.29 * *$ \\
Honey & $2.13 \pm 0.24$ & $2.54 \pm 0.29$ \\
Herby & $2.45 \pm 0.30$ & $1.97 \pm 0.30$ \\
Sweet pepper & $2.47 \pm 0.21$ & $1.96 \pm 0.26$ \\
* p $<0.05 * * p<0.01$ & &
\end{tabular}

(2002) obtained similar results in their sensory measurements and demonstrated that this could happen when samples are very similar in their sensory properties and panellists are unable to differentiate between them easily. Added to that are the individual assessor's existing differences, which is common in sensory studies (Brockhoff \& Skovgaard, 1994; Naes \& Langsrud, 1998; Kreutzmann et al., 2007).

\section{Effect of polyphenol concentration on aroma perception}

The ANOVA of the sensory, volatile compounds and physicochemical data showed those variables that affected polyphenol levels. Differences in physicochemical data were not significant among polyphenol ranges: $\mathrm{pH}\left[F_{(1,26)}=0.011\right]$, dry extract $\left[F_{(1,26)}=2.768\right]$, tritatable acidity $\left[F_{(1,26)}=1.182\right]$, reducing sugars $\left[F_{(1,26)}=0.011\right]$ and density $\left[F_{(1,26)}=0.011\right]$. The ethanol percentage was not a significant factor in the selected wines $\left[F_{(1,26)}=0.362\right]$, thus it was ensured that the range of ethanol selected (10.5 to $13.5 \%$ ) was suitable for studying the incidence of polyphenol levels in aroma perception (Escudero et al., 2007; Goldner et al., 2009).

The effect of the polyphenol content was classed as suppressing or accentuating, depending on whether the 
intensity values increased or decreased between the ranges. The perception of red wine aroma was affected by polyphenol levels in five attributes (one at $P<0.05$ and four at $P<0.01$, Table 2). The aroma intensity of fruity, citrus, strawberry, cooked fruit and floral attributes all decreased when the levels of polyphenol increased; the aroma suppression observed indicated polyphenol interaction with volatile species. This was in agreement with Sáenz-Navajas et al. (2010) who reported an intense effect of the non-volatile matrix on the aroma perception of wine. These authors also stated that the presence of a red wine matrix with the highest polyphenol content brought about significant increases in dry fruit, vegetal, animal and undergrowth notes and significant decreases in fruitiness in yellow, citrus and exotic fruits. Our results showed a tendency to the accentuation of spicy, herby and sweet pepper aromas but this was not significant (Table 2).

Seventeen aroma compounds were identified: ethyl acetate, isobutanol, n-pentanol, 3-methyl butanol, 2-methyl butanol, toluene, furfural, ethyl isovalerate, hexanol, isoamyl acetate, ethyl hexanoate, 2-phenyl ethanol, diethyl succinate, ethyl octanoate, ethyl phenylacetate, vitispirane and ethyl decanoate. Applying an ANOVA of the GC data showed that the polyphenol content on volatile substances detected by HS-SPME was not significant, except for 2-methyl butanol, which displayed a relative minor area when the polyphenol level increased.

The polyphenols naturally present in wine affected the olfactory perception, but it was not evident by HS-SPMEGC-MS. Aronson and Ebeler (2004) found similar results under different conditions: the effect of polyphenol addition on the detection by HS-SPME was non-significant at low concentrations of flavour in model solutions.

Here it is important to take into account the type of sample. This experiment was conducted on samples with a polyphenol content that was not modified with added tannins, gallic acid or others; the wide range of polyphenol concentration was naturally present in the complex matrix of the wine and could have been due to climate conditions, region of origin (Frankel et al., 1995) or vinification technology (Villariño et al., 2006). In the present study, the suppressing effect of polyphenols on fruitiness and floral aromas was found to be noteworthy.

Since the extraction efficiency of red wine aroma compounds by HS-SPME strongly depends on their polarity, their affinity to the fibre-coated phases, the temperature and time on the equilibrium (De la Calle García et al., 1998; Baptista et al., 2001), it is probable that, in the results reported in this paper, interactions between phenol and volatile compounds were not significant enough to be measured by SPME fibre. The PDMS fibre used in this study is considered by many authors as the most suitable for adsorbing volatile compounds from wines and other alcoholic beverages (Kafkas et al., 2006). Dietz and co-workers (2006) stated that, in general, a wide range of possible solutions exist for a given analytical problem in SPME. Therefore, it is known that fibres with an additional adsorbent phase such as DVB or Carboxen are the most effective (Shirey, 1999), and it is usually necessary to combine different methods to obtain a complete extraction of volatile compounds (Mamede \& Pastore, 2006). Sáenz-Navajas et al. (2010) confirmed that the red wine non-volatile matrix has a higher retention power, which reduces the volatility of the compounds; scores of Gas Chromatography-Olfactometry data tended to be smaller on red wines with the highest total polyphenol content. The effects resulting from the presence of matrices from red wines are more complex, slightly weaker and more matrix-dependent.

The Pearson correlation allows evaluation of the variables influenced by the polyphenol levels in a linear way; coefficients among sensory attributes are displayed in Table 3, the polyphenol concentration always being incorporated. Fruity aroma showed positive coefficients among strawberry, plum, cooked fruit, floral and honey aromas, but negative coefficients with herby aromas, whereas spicy aromas displayed a positive correlation with herby and sweet pepper attributes. Moreover, this coefficient allowed the evaluation of the variables

TABLE 3

Pearson correlations between sensory descriptors and polyphenol content of 28 selected wines.

\begin{tabular}{|c|c|c|c|c|c|c|c|c|c|c|c|}
\hline & $\begin{array}{c}\text { Poly- } \\
\text { phenols }\end{array}$ & Fruity & Citrus & Strawberry & Plum & Raisin & Spicy & $\begin{array}{c}\text { Cooked } \\
\text { fruit }\end{array}$ & Floral & Honey & Herby \\
\hline Fruity & $-0.555 * *$ & & & & & & & & & & \\
\hline Citrus & $-0.378 *$ & 0.289 & & & & & & & & & \\
\hline Strawberry & -0.284 & $0.624 * * *$ & 0.283 & & & & & & & & \\
\hline Plum & -0.215 & $0.508 * *$ & 0.149 & $0.515 * *$ & & & & & & & \\
\hline Raisin & -0.076 & 0.267 & 0.191 & 0.293 & $0.564 *$ & & & & & & \\
\hline Spicy & 0.133 & -0.314 & $-0.616 * *$ & -0.181 & -0.030 & 0.226 & & & & & \\
\hline $\begin{array}{l}\text { Cooked } \\
\text { fruit }\end{array}$ & -0.306 & $0.526 * *$ & 0.008 & 0.249 & $0.611 *$ & $0.505 *$ & 0.135 & & & & \\
\hline Floral & $-0.469 *$ & $0.403 *$ & 0.210 & $0.492 * *$ & $0.485 *$ & 0.369 & -0.126 & $0.592 *$ & & & \\
\hline Honey & -0.199 & $0.475^{*}$ & -0.252 & $0.483 * *$ & $0.440 *$ & $0.605^{*}$ & 0.287 & $0.563 * *$ & 0.374 & & \\
\hline Herby & 0.138 & $-0.500 * *$ & -0.051 & -0.355 & -0.206 & -0.273 & $0.532 * *$ & 0.000 & -0.206 & -0.216 & \\
\hline $\begin{array}{l}\text { Sweet } \\
\text { pepper }\end{array}$ & 0.309 & -0.305 & $-0.548 * *$ & $-0.402 *$ & -0.168 & 0.204 & $0.718 * *$ & 0.198 & -0.150 & 0.270 & $0.438 *$ \\
\hline
\end{tabular}




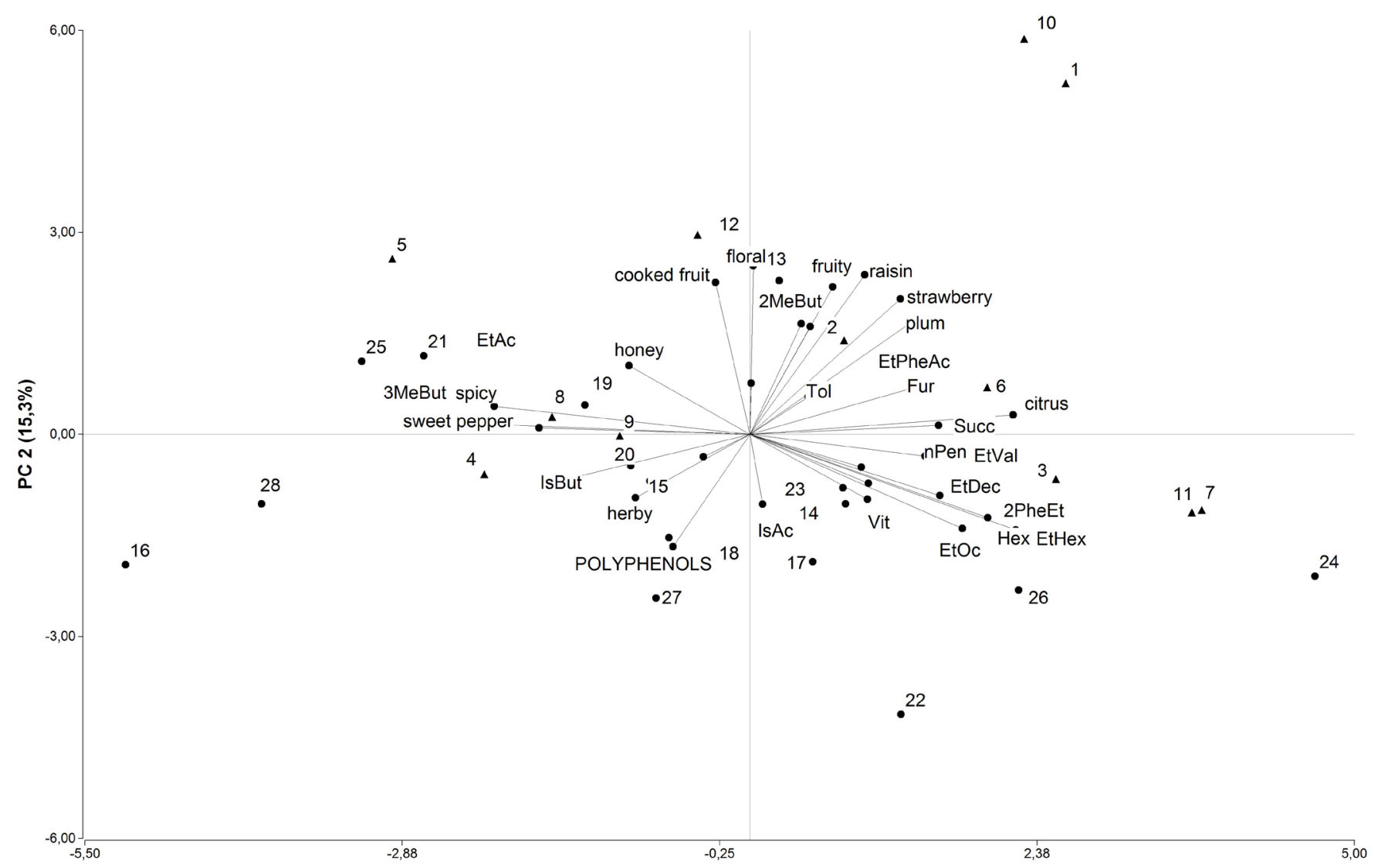

FIGURE 1

Principal component analysis of the aroma attributes and volatile compounds of 28 wines at two polyphenol levels (Low: samples 1 to 12 and High: samples 13 to 28 ).

influenced by polyphenol levels: fruity, citrus, cooked fruit and floral aromas correlated in a negative way.

The Pearson coefficients among aroma and GC data showed positive correlation between fruity $(P<0.05)$, plum $(P$ $<0.05)$, cooked fruit $(P<0.01)$ and floral $(P<0.05)$ aromas with 2-methyl butanol; citrus with vitispirano $(P<0.05)$; strawberry with ethyl succinate $(P<0.05)$ and floral and plum with ethyl phenyl acetate $(P<0.05)$ (Data not shown). This accompanies the affirmation by Goyert et al. (2007): olfactory receptors do not act as detectors of isolated molecular features, but more likely recognise entire molecules closely associated with perceived olfactory qualities.

\section{Principal component analysis of sensory and GC data}

This multivariate technique of data analysis has been used to explain wine differentiation and to obtain more information on the variables that mainly influence similarities and differences. Principal component analysis (PCA) of sensory and GC variables accounted for a $74.7 \%$ of the variance among samples. The results obtained for all studied samples of wines were projected onto a two-dimensional plot defined by the first two Principal Components, PC2 vs. PC1, where the polyphenol concentration was always taken into account, as is shown in Fig. 1. Citrus, strawberry, plum, fruity, floral, raisin, n-pentanol, hexanol, toluene and furfural attributes were positively correlated along $\mathrm{PC} 1$. In addition, most esters were always associated with the above attributes, denoting their relation with fruitiness aromas
(Escudero et al., 2007), contrary to sweet pepper, spicy, herby, 3-methyl butanol, isobutanol, ethyl acetate and the polyphenol concentration. It can be seen that wines with low polyphenol levels (from No. 1 to 12 ) clustered with most of the volatile compounds, fruitiness aromas, floral, cooked fruit and honey attributes as opposed to the majority of wines with high polyphenol levels (from No. 13 to 28), which clustered around 3-methyl butanol, isobutanol, ethyl hexanoate, and vegetable aromas along with polyphenol content.

\section{CONCLUSIONS}

The aroma of Malbec wine was modified with increasing polyphenol levels denoting interaction effects between polyphenols naturally present and volatile substances. One consequence of this interaction was the suppressing effect on fruitiness aromas when polyphenols ranged from 4.5 to $7.2 \mathrm{~g} / \mathrm{L}$ for samples with $13.5 \%$ maximum ethanol. Changes in headspace and matrix concentration could be related to relative changes in sensory intensity but the effect was not significant, neither by HS-SPME-GC-MS nor by physicochemical composition. The results suggest that winemakers could monitor polyphenol concentration and make decisions during the wine process, in order to improve the fruitiness aroma. The results are limited to two ranges of polyphenols and Malbec wine samples; they may be confirmed by further studies on other sets of samples. 


\section{ABBREVIATIONS}

EtAc = ethyl acetate; EtDec = ethyl decanoate; EtHex = ethyl hexanoate; EtOc = ethyl octanoate; EtPheAc = ethyl phenylacetate; EtVal = ethyl isovalerate; Fur = furfural; Hex $=$ hexanol; IsAc $=$ isoamyl acetate; IsBut $=$ isobutanol; nPen $=$ n-pentanol; Succ $=$ diethyl succinate; Tol = toluene; Vit $=$ vitispirane; $2 \mathrm{MeBut}=2$-methyl butanol; $2 \mathrm{PheEt}=2$-phenyl ethanol; 3MeBut = 3-methyl butanol.

\section{LITERATURE CITED}

Adams, R.P., 2007. Identification of essential oil components by gas chromatography/quadrupole mass spectroscopy. Allured: Carol Stream, IL.

AOAC, 1990. Wines. In: Herlich, K. (ed). Official methods of analysis of Association of Official Analytical Chemists, vol II $\left(15^{\text {th }}\right.$ ed $)$. Arlington, Virginia. Ch. 28 .

Arnold, R.A. \& Noble, A.C., 1978. Astringency of grape seed phenolics in a model wine solution. Am. J. Enol. Vitic. 29, 150-152.

Aronson, J. \& Ebeler, S.E., 2004. Effect of polyphenol compounds on the headspace volatility of flavors. Am. J. Enol. Vitic. 55, 13-21.

ASTM, 1992. Manual on descriptive analysis testing, MNL 13. American Society for Testing and Materials, Philadelphia, PA.

Baptista, J.A.B., Tavares, J.F. da P. \& Carvalho, R.C.B., 2001. Comparison of polyphenols and aroma in red wines from Portuguese mainland versus Azores Islands. Food Res. Int. 34, 345-355.

Brockhoff, P. \& Skovgaard, I., 1994. Modelling individual differences between assessors in sensory evaluations. Food Qual. and Pref. 28, 404-409.

Condelli, N., Dinnella, C., Cerone, A., Monetelone, E. \& Bertucciolli, M., 2006. Prediction of perceived astringency induced by phenolic compounds II: Criteria for panel selection and preliminary application on wine samples. Food. Qual. and Pref. 17, 96-107.

De la Calle García, D., Reinchenbäger, M. \& Danzer, K., 1998. Analysis of wine bouquet components using headspace solid-face microextraction-capillary gas chromatography. J. High Resol. Chromatogr. 21, 373-377.

Dietz, C., Sanz, J. \& Camara, C., 2006. Recent developments in solid-phase microextraction coatings and related techniques. J. Chromatogr. A 1103, 183192.

Dufour, C. \& Bayonove, C.L., 1999. Interactions between wine polyphenols and aroma substances. An insight at the molecular level. J. Agric. Food Chem. $47,678-684$.

Escudero, A., Campo, E., Fariña, L., Cacho, J. \& Ferreira, V., 2007. Analytical characterisation of the aroma of five premium red wines. Insights into the role of odor families and the concept of fruitiness of wines. J. Agric. Food Chem. $55,4501-4510$.

Faitová, K., Hejtmánková, A., Lachman, J., Pivec, V. \& Dudjak, J., 2004. The contents of total polyphenolic compounds and trans-resveratrol in white Riesling originated in the Czech Republic. Czech J. Food Sci. 22, 215-221.

Frankel, N.E., Waterhouse, L.A. \& Pierre, L.T., 1995. Principal phenolic phytochemicals in selected California wines and their antioxidant activity in inhibiting oxidation of human low-density lipoproteins. J. Agric. Food Chem. 43, 890-894.

Gawel, R., 1998. Red wine astringency: A review. Aust. J. Grape Wine Res. 4, 74-95.

Goldner, M.C. \& Zamora, M.C., 2007. Sensory characterisation of vitis vinifera $\mathrm{cv}$. Malbec wines from seven viticulture regions of Argentina. J. Sens. Studies 22, $520-532$.
Goldner, M.C., Zamora, M.C., Di Leo Lira, P., Gianninoto, H. \& Bandoni, A., 2009. Effect of ethanol level on the perception on the aroma attributes and the detection of volatile compounds in red wine. J. Sens. Studies 24, 243-257.

Goyert, H.F., Frank, M.E., Gent, J.F. \& Hettinger, T.P., 2007. Characteristic component odors emerge from mixtures after selective adaptation. Brain Res. Bulletin 72, 1-9.

INFOSTAT. 2009. InfoStat, version 2009. Grupo InfoStat, FCA, Universidad Nacional de Córdoba. Editorial Brujas, Argentina.

IRAM, 1996. Análisis sensorial metodología. Iniciación y entrenamiento de los evaluadores en la detección y reconocimiento de olores. Norma 20006, Instituto Argentino de Normalización, Buenos Aires, Argentina.

Kafkas, E., Cabaroglu, T., Selli, S., Bozdağan, A., Kürkcüoğlu, M., Paydas, S. \& Başer, K.H.C., 2006. Identification of volatile compounds of strawberry wine using solid-phase microextraction techniques coupled with gas chromatography-mass spectrometry. Flavour and Fragr. J. 21, 68-71.

Kreutzmann, S., Thybo, A.K. \& Bredie, W.L.P., 2007. Training of a sensory panel and profiling of winter hardy and coloured carrot genotypes. Food Qual. and Pref. 18, 482-489.

Lesschaeve, I. \& Noble, A.C., 2005. Polyphenols: Factors influencing their sensory properties and their effects on food and beverage preferences. Am. J. Clin. Nutr. 81, 330-335.

Lund, C.M., Nicolau, L., Gardner, R.C. \& Kilmartin, P.A., 2009. Effect of polyphenols on the perception of key aroma compounds from Sauvignon Blanc wine. Aust. J. Grape and Wine Res. 15, 18-26.

Mamede, M.E.O. \& Pastore, G.M., 2006. Study of methods for the extraction of volatile compounds from fermented grape must. Food Chem. 96, 586-590.

Monteleone, E., Condelli, N., Dinniella, C. \& Bertuccioli, M., 2004. Prediction of perceived astringency induced by phenolic compounds. Food Qual. and Pref. $15,761-769$.

Naes, T. \& Langsrud, O., 1998. Fixed or random assessors in sensory profiling. Food Qual. and Pref. 9, 145-152.

Pawliszyn, J. 1999. Quantitative aspects of SPME. In: Pawliszyn, J. (ed). Applications of solid phase microextraction, Royal Society of Chemistry, Cambridge, U.K. pp. 3 - 21 .

Retta, D., Gattuso, M., Gattuso, S., Di Leo Lira, P., Van Baren, C. \& Bandoni, A. 2009. Volatile constituents of five Baccharis species from the Northeastern Argentina. J. Braz. Chem. Soc. 20, 1379-1384.

Sáenz-Navajas, M.P., Campo, E., Culleré, L., Fernández-Zurbano, P., Valentin, D. \& Ferreira, V., 2010. Effects of the nonvolatile matrix on the aroma perception of wine. J. Agric. Food Chem. 58, 5574-5585.

Shirey, R.E., 1999. SPME fibers and selection for specific applications. In: Scheppers Wercinski, S.A. (ed). Solid phase microextraction: A practical guide. Dekker, New York. pp. $59-110$.

Stone, H. \& Sidel, J.L., 1993. Sensory evaluation practices ( $2^{\text {nd }}$ ed). Elsevier Academia Press. USA

Tang, C., Hsieh, F., Heymann, H. \& Huff, H.E., 1999. Analyzing and correlating instrumental and sensory data: A multivariate study of physical properties of cooked wheat noodles. J. Food Qual. 22, 193- 211.

Vidal, S., Francis, L., Noble, A., Kwiatkowski, M., Cheynier, V. \& Waters, E., 2004. Taste and mouth-feel properties of different types of tannin-like polyphenolic compounds and anthocyanins in wine. Anal. Chem. Acta 513, $57-65$.

Villariño, D., Fernández-Pachon, M.S., Troncoso, A.M. \& García-Parrilla, M.C., 2006. Influence of enological practices on the antioxidant activity of wines. 
WILEY/NIST. 2005. Registry of Mass Spectral Data ( $8^{\text {th }}$ ed). Wiley \& Sons, New York.
Zamora, M.C. \& Guirao, M., 2002. Analyzing the contribution of orally perceived attributes to the flavor of wine. Food Qual. and Pref. 13, 275-283. 